\title{
Pulmonary toxicity generated from radiotherapeutic treatment of thoracic malignancies (Review)
}

\author{
GUODONG DENG ${ }^{1}$, NING LIANG ${ }^{1}$, JIAN XIE $^{1}$, HUI LUO $^{2}$, LILI QIAO $^{3}$, JINGXIN ZHANG $^{4}$, \\ DAWEI WANG ${ }^{5}$ and JIANDONG ZHANG ${ }^{1}$
}

\author{
${ }^{1}$ Department of Radiation Oncology, Qianfoshan Hospital, Shandong University, Jinan, Shandong 250014; \\ ${ }^{2}$ Department of Radiation Oncology, Henan Cancer Hospital, Zhengzhou University, Zhengzhou, Henan 450001; \\ ${ }^{3}$ Department of Oncology, The Fifth People's Hospital of Jinan, Jinan, Shandong 250022; ${ }^{4}$ Division of Oncology, \\ Graduate School, Weifang Medical College, Weifang, Shandong 261053; ${ }^{5}$ Department of Radiology, \\ Qianfoshan Hospital Affiliated to Shandong University, Jinan, Shandong 250014, P.R. China
}

Received October 6, 2015; Accepted March 14, 2017

DOI: $10.3892 / 01.2017 .6268$

\begin{abstract}
Radiation-induced lung injury (RILI) remains a major obstacle for thoracic radiotherapy for the treatment of lung cancer, esophageal cancer and lymphoma. It is the principal dose-limiting complication, and can markedly impair the therapeutic ratio as well as a patient's quality of life. The current review presents the relevant concepts associated with RILI, including the pathogenic mechanisms and the potential treatment strategies, so as to achieve a general understanding of this issue. RILI comprises an acute radiation pneumonitis phase and subsequent late lung fibrosis. The established assessment criteria are clinical manifestations, imaging changes and the necessity for medical assistance. Risk factors are also considered in order to optimize treatment planning. Due to the underlying molecular mechanisms of RILI, the present review also discusses several targeted pharmacological approaches for its treatment, as well as corticosteroid therapy.
\end{abstract}

\section{Contents}

1. Introduction

2. Pathogenic mechanism

3. Clinical manifestations

4. Imaging findings

5. Predictive factors

6. Grading systems

7. Treatments

8. Conclusions

Correspondence to: Dr Jiandong Zhang, Department of Radiation Oncology, Qianfoshan Hospital, Shandong University, 16766 Jingshi Road, Jinan, Shandong 250014, P.R. China

E-mail: zhangjd165@sina.com

Key words: thoracic malignancy, radiotherapy, radiation pneumonitis, lung fibrosis

\section{Introduction}

Radiotherapy (RT) is one of the main therapies for lung malignancies. As an organ that is sensitive to ionizing radiation, the lung tends to be easily damaged by radiation beams (1). Radiation-induced lung injury (RILI) is a major dose-limiting complication that develops in 7-37\% of patients who undergo definitive RT for lung cancer (1-5). Although the application of modern radiation techniques has allowed for more accurate determination of target volume and a reduction of the dose administered to the normal lung tissues, acute radiation pneumonitis (RP) and late lung fibrosis have not been eradicated (6-8). Advanced non-invasive imaging techniques have provided a visual understanding of the disease, which has improved the rates of diagnosis and cure of RILI (9-11). In addition, various factors predictive of RILI, particularly dosimetric parameters, can contribute to the optimization of treatment planning (12). Classical countermeasures consisting of corticosteroids have demonstrated only an ameliorating effect on RILI, but not prevention of disease progression (1). Fortunately, with advances in research into its pathogenic mechanisms, several promising pharmacological interventions for RILI have been developed (13-15). Nevertheless, these novel agents have only been studied pre-clinically or in early clinical trials thus far. Therefore, further research is still required.

\section{Pathogenic mechanisms}

RILI includes an acute inflammatory phase, presenting as RP (1-3 months after RT), and a chronic fibrotic phase, presenting as radiation fibrosis (6-24 months after RT) (1). The pathological modifications associated with RILI in these two phases comprise a dynamic sequential process: Inflammation-induced depletion of alveolar surface cells, infiltration of inflammatory cells into the interstitial space, exudative response, and fibrotic changes (16).

The alveolar epithelium in humans is composed of two types of cells. Type I pneumocytes, which are squamous epithelial cells covering $>90 \%$ of the alveolar surface, are the 
first to be damaged by radiation beams. Following irradiation, type I cells undergo apoptosis, which promotes the proliferation of type II pneumocytes and leads to repopulation of the alveolar epithelium. Type II pneumocytes are cuboidal cells that are specialized in synthesizing and secreting pulmonary surfactants; this substance covers the alveolar surface and adjusts the surface tension. Thus, hyperplasia of type II cells resulting from radiation, and the associated surfactant overproduction, can be a non-specific indicator of pulmonary damage and reconstruction $(17,18)$. Recent studies on animal models demonstrated that irradiated alveolar epithelial cells play an important role in pulmonary fibrosis $(19,20)$.

Following RT, various cytokines are released. Activated alveolar macrophages can produce chemotactic and mitogenic cytokines, which act on immunocytes, fibroblasts and endothelial cells. These cytokines lead to the local recruitment of inflammatory leukocytes, including macrophages. Subsequently, leukocytes adhere to the endothelial cells of microvasculature and transmigrate to the interstitium; these cells further secret cytokines to recruit and activate additional immunocytes to trigger the inflammatory process (17). Tumor necrosis factor- $\alpha$ (TNF- $\alpha$ ) is a type of proinflammatory and profibrotic cytokine that is synthesized by activated macrophages (21). During the course of fibrosis, TNF- $\alpha$ plays an important role in the secretion of proinflammatory cytokines, such as interleukin (IL)-1 and IL-6, in the proliferation of fibroblasts, and in the production of extracellular matrix (ECM) proteins. Under the hypoxic conditions in lung tissue following radiation, the macrophages will also persistently produce reactive oxygen species (ROS), which promote pulmonary injury and fibrosis (17).

Pulmonary fibrosis results from the accumulation of fibroblasts, myofibroblasts, fibrin and ECM proteins in the interstitium, followed by the pathological changes of scar formation (22). However, the molecular mechanism remains unclear, and numerous studies have been conducted to investigate related factors (17,22-31). Myofibroblasts are recognized as crucial factors in pulmonary fibrosis. Commonly, myofibroblasts are considered to be generated from resident fibroblasts, but recent evidence has indicated that damaged epithelial cells may directly provide myofibroblasts by means of epithelial-mesenchymal transition (EMT) (23). Nagarajan et al (24) revealed that a related pathway mediates EMT in irradiated alveolar type II epithelial cells. In a study by Phillips et al (25), it was demonstrated that circulating fibrocytes are associated with the pathogenesis of lung fibrosis.

Transforming growth factor- $\beta$ (TGF- $\beta$ ) is a key cytokine in the fibrotic process; it is derived mainly from inflammatory cells, and also from pneumocytes and fibroblasts to some degree (17). In epithelial cells, upregulated TGF- $\beta$ stimulates the expression of Smad proteins, which induce the activation of other transcription factors. TGF- $\beta /$ Smad signaling plays an important role in promoting pulmonary fibrosis in various ways, including ROS production, activation of myofibroblasts and fibrocytes, and ECM synthesis (31). In a study by Yano et al (26), the Smad pathway was shown to contribute to radiation-induced lung fibrosis via the production of type I collagen, and not mitogen-activated protein kinase (MAPK). TGF- $\beta$ can act as a powerful stimulator of collagen synthesis through modulating the transition from a human lung fibroblast to a myofibroblast phenotype, which facilitates lung fibrosis $(27,28)$.

In addition to TGF- $\beta$, inflammatory cytokines derived from $\mathrm{T}$ helper ( $\mathrm{Th}$ ) cells also contribute to lung fibrosis. Han et al (29) noted that, in mice, Th2 immune response-associated factors, including IL-13, GATA-binding protein 3 and arginase 1, may be crucial in the fibrotic process. ECM remodeling, which involves collagen-degrading matrix metalloproteinases (MMPs) and tissue-inhibitors of MMPs, also augments the fibrotic process (30). Yang et al (30) suggested that MMP-2 and MMP-9, which degrade collagen IV in the basement membrane, were overexpressed in mice post-radiation during the inflammatory response, and destroyed the normal structure of the lung tissue.

\section{Clinical manifestations}

In the acute phase of RILI, typical clinical symptoms including dyspnea, ranging from mild to serious, and dry cough, which is observed in $\sim 60 \%$ of patients with RP. Low-grade temporal fever is uncommon, and occurs in $\sim 10 \%$ of cases. Upon physical examination in cases of suspected RILI, there may be no apparent abnormalities. However, rare signs such as pleural friction rub, moist rales, and consolidation may be heard occasionally in some cases, in addition to the common presentations (1). These manifestations may be complicated by pre-existing lung disease, such as chronic obstructive pulmonary disease (32). The incidence of fatal RP is low; in a study by Palma et al (33), it appeared in only $1.9 \%$ of cases in all patients who accepted concurrent chemoradiation therapy for non-small cell lung cancer (NSCLC).

Radiation fibrosis, which develops in the later phase of RILI, is a scarring disease that can markedly reduce the pulmonary function (32). It may be developed without the patient having suffered the acute phase. Different degrees of respiratory difficulty can occur in fibrotic patients. Chronic pulmonary insufficiency commonly evolves in patients with a large volume of irradiated lung tissue, and this facilitates the development of pulmonary hypertension or even cor pulmonale (pulmonary heart disease) (1). As a restrictive disease, pulmonary function test outcomes in RP patients, including the first expiratory volume in $1 \mathrm{sec}$ (measuring gas movement) and the forced vital capacity (indicating lung capacity), are reduced (16). Carbon monoxide diffusion capacity (DLCO), an essential test that evaluates the gas diffusion condition of RILI patients, decreases significantly when the local radiation dose in normal lung tissue totals $\geq 13$ Gy (34). DLCO loss tends to increase according to radiation dose $(\sim 72 \%$ in patients who received $10-20 \mathrm{~Gy}$, and $\sim 90 \%$ in patients who received $>20$ Gy) (34). However, the severity of lung injury is usually defined by the presentation of clinical symptoms and the corresponding treatment strategies, not pulmonary function indexes $(16,34)$.

\section{Imaging findings}

In cases of suspected RILI, non-invasive radiological imaging, including chest radiography, computed tomography (CT), single-photon emission CT (SPECT), magnetic resonance imaging (MRI) and $18 \mathrm{~F}$-fluorodeoxyglucose positron 
emission tomography (FDG-PET), may be applied to evaluate the damaged region and potentially predict the corresponding clinical features (6). Various radiological abnormalities associated with RILI may be observed in the different phases of lung pathological injury. An increased density on areas of CT images is associated with inflammatory reactions during the acute phase (7). Not all radiological appearances of RILI are accompanied by clinical symptoms; $50-100 \%$ of lung cancer patients who have undergone RT tend to present with radiological signs of RILI, whereas only 5-35\% develop clinical symptoms (35-37). Thus, imaging examinations are important for patients who have undergone thoracic irradiation. The frequency of imaging examinations is determined on the basis of the sensitivity of the specific radiographic assessment; it is reported that $\mathrm{CT}$ is more sensitive and reveals $\mathrm{RP}$-associated changes earlier compared with chest radiography, as it provides $3 \mathrm{D}$ visualization of the lung (6).

CT findings. For conventional thoracic RT, Libshitz and Shuman (38) classified the lung injury-associated CT findings into four types: i) Ground-glass attenuation or homogeneous consolidation; ii) patch-like increased density in the irradiated area that is not consistent with the portal shape; iii) scattered consolidation that is consistent with the portal shape but has a poorly-defined border; and iv) solid consolidation that involves the entire region of irradiated lung tissue. The former patterns correspond to the acute phase of inflammatory exudation, while the latter patterns correspond to the late phase of lung fibrosis.

With the improvement of radiation methods, certain advanced techniques, including 3D conformal RT (3DCRT), intensity-modulated RT (IMRT), and stereotactic body RT (SBRT), which are able to deliver a maximized tumoricidal dose to tumors while minimizing the irradiation of normal lung tissues, have been developed.

3DCRT is a modern and sophisticated technique that applies multiple radiation beams to form a conformal radiation field properly fitted to target volumes. This method greatly reduces the rate of RILI and has an improved curative effect compared with conventional 2-dimensional radiotherapy. In patients with NSCLC undergoing 3DCRT, CT images for lung areas with RILI can develop into altered conventional fibrosis (increased density, volume loss, and bronchiectasis in a shrunken extent compared with conventional radiotherapy), scar-like patterns (an opacity change in tumor tissues) or mass-like patterns (7).

In IMRT, intensity-modulated radiation is delivered to irregularly shaped tumor volumes by means of the dynamic multileaf collimators on the basis of 3DCRT. Given that tumor location, size and disease entity determine the radiation portal and beam angles, RILI may differ in shape and distribution depending on tumor features (39).

SBRT is a novel RT technique in which multiple radiation portals are applied from different directions, allowing good treatment effects for medically inoperable early-stage NSCLC patients. Radiation lesions in normal tissue are limited to the periphery of the tumor and have a complex shape. In patients who have undergone SBRT, the CT findings associated with RILI conform more closely to the shape of the tumor, and there is no distinct boundary dividing the irradiated and non-irradiated lung, in contrast to conventional RT (8).
Figs. 1 and 2 show the typical CT imaging findings of RP.

SPECT findings. CT scans depict density modifications of lung tissue in RILI patients that are consistent with the 3D dose distribution map. However, SPECT has been demonstrated to be a more sensitive examination than $\mathrm{CT}$ imaging for assessing lung injury, by evaluating regional lung perfusion and ventilation functions $(6,40)$. Physiologically, lungs tend to adjust blood flow according to ventilation changes rather than adjust ventilation according to blood flow changes. Therefore, perfusion is a more sensitive factor than ventilation for predicting RILI (6). Zhang et al (41) conducted a study of 20 patients with locally advanced NSCLC who received radical- or non-radical-dose IMRT, in order to quantitatively evaluate early abnormalities in lung perfusion using SPECT imaging. SPECT was conducted prior to and immediately subsequent to IMRT. The study calculated lung perfusion index (LPI) with regard to blood flow through radioactive count. The results revealed no statistically significant difference between the LPIs pre- and post-IMRT ( $\mathrm{P}=0.135)$. In the radical-dose group, LPI difference was not statistically significant $(\mathrm{P}=0.993)$; by contrast, the difference was significant in non-radical-dose group $(\mathrm{P}=0.025)$. Thus, SPECT scanning is useful in evaluating early alterations in perfusion in patients undergoing non-radical-dose IMRT. Currently, SPECT scanning in assessing perfusion is primarily judged by visual inspection by physicians; therefore, it is inevitably biased and it is challenging to identify early subtle changes in perfusion (9). Thus, radioactive counts in qualifying SPECT images are required.

MRI findings. In previous studies, MRI findings have been described for RILI lesions in animal models and human patients $(10,11)$. In a Japanese study conducted by Shioya et al (10), MRI was used to measure the extent of lung injury in rats that had undergone hemithoracic radiation, indicating that MRI may be a sensitive technique for detecting early RILI. Ireland et al (11) compared helium-3 MRI ( $\left.{ }^{3} \mathrm{He}-\mathrm{MRI}\right)$ acquired from patient with NSCLC pre- and post-external-beam RT. In their study, all 5 patients with pathologically confirmed NSCLC received CT and ${ }^{3} \mathrm{He}-\mathrm{MRI}$ ventilation imaging. Post-irradiation, 3 patients developed pneumonitis that was apparent on CT images. Concurrently, a significant reduction of ${ }^{3} \mathrm{He}-\mathrm{MRI}$ ventilation was observed in these 3 patients on post-irradiation imaging compared with pre-irradiation imaging $(\mathrm{P}=0.02)$. This indicates that ${ }^{3} \mathrm{He}-\mathrm{MRI}$ is a potential method for describing RP by means of expressing the reduction in ventilation.

PET findings. FDG-PET is a type of metabolic imaging technology that can present regional functional information, and which has the potential to evaluate RILI. In a study by Hart et al (42), pulmonary metabolic radiation response, a parameter generated from FDG-PET analysis, was found to be associated with an increased probability of developing RILI ( $\mathrm{P}=0.033)$. McCurdy et al (9) also demonstrated that the FDG-uptake dose-response was associated with symptomatic RP in patients with lung cancer treated with thoracic RT. Additionally, combined PET-CT and PET-MRI, which can present anatomical and metabolic information, are promising techniques (43). Studies indicated that ventilation/perfusion 


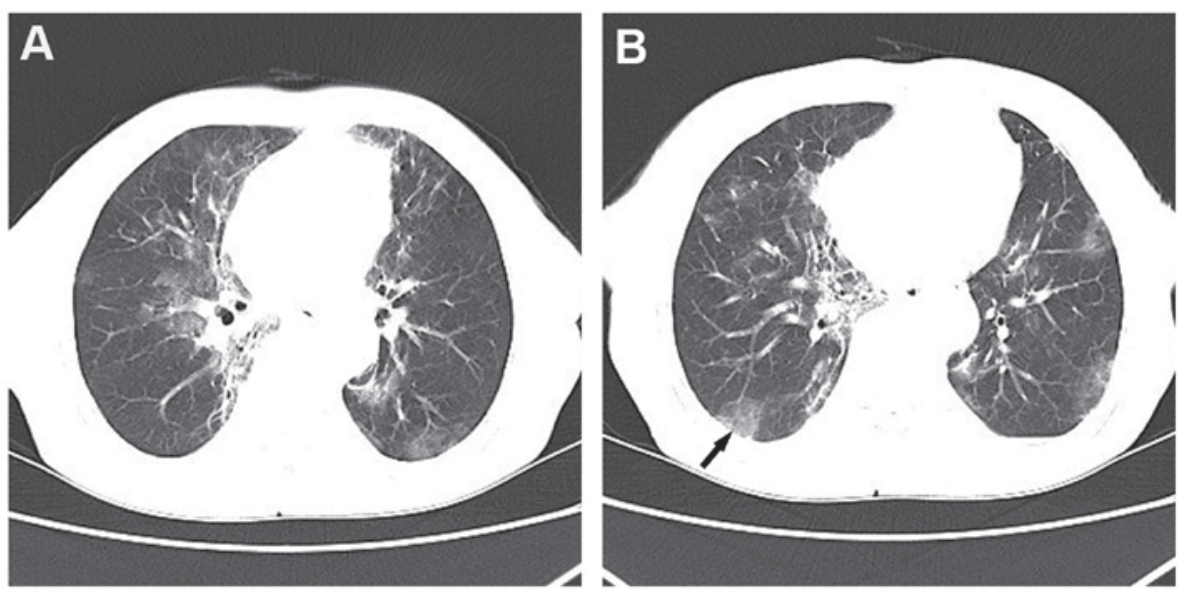

Figure 1. Computed tomography images (A, before radiotherapy; B, post radiotherapy) of a 63-year-old woman with esophageal cancer. Following radiation of $\leq 59.4 \mathrm{~Gy}$, certain imaging changes were apparent in panel B, including scattered areas of patchy density in the lung (noted by the black arrow in panel B). The clinical manifestations of this patient were mild, with only a dry cough reported.
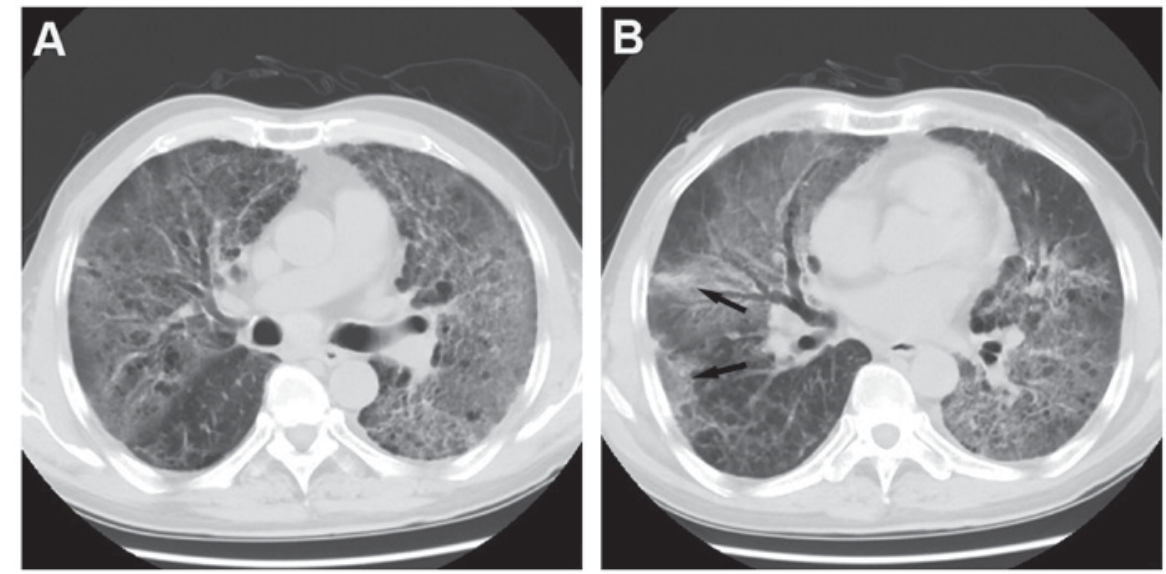

Figure 2. Computed tomography images of a 58-year-old man with lung cancer (A, before radiotherapy; B, post radiotherapy). Although the $\mathrm{V}_{20}(\%$ volume of lung that received $\geq 20$ Gy radiation) for the whole lung was $23 \%$, typical imaging findings of RP were visible, including patchy infiltration and density (noted by the black arrows in panel B). This patient presented with severe symptoms, including a prolonged high fever with yellow mucus production, which were insensitive to standard antibacterial agents.

index of PET-CT imaging was able to predict the occurrence rate of RILI and PET-CT could be recommended to differentiate RILI from cancer recurrence $(44,45)$.

\section{Predictive factors}

Parameters from dose-volume histograms (DVHs). DVHs generated from 3DCRT planning have been investigated in numerous studies, and have revealed the dosimetric parameters that are able to predict RILI caused by external-beam RT. $V_{\text {dose }}$, mean lung dose (MLD) and normal tissue complication probability (NTCP), which are described below, are three dosimetric parameters with high predictive value for RILI that have been studied extensively (2). These parameters may assist clinicians with optimizing radiation treatment planning.

$V_{\text {dose }}$ and $M L D$. The definition for $\mathrm{V}_{\text {dose }}$ (e.g., $\mathrm{V}_{5}, \mathrm{~V}_{10}, \mathrm{~V}_{20}, \mathrm{~V}_{30}$ or $\mathrm{V}_{40}$ ) is described as the percentage of the whole CT-measured volume of the irradiated lung that received equal to or more than the threshold dose $(5,10,20,30$ or $40 \mathrm{~Gy}$, respectively).
MLD represents the mean dose applied over the whole lung volume measured by $\mathrm{CT}$ imaging. Among the dosimetric factors, $\mathrm{V}_{20}$ and MLD are the most frequently used parameters for predicting RILI (33).

Hernando et al (3) conducted a study of 201 patients with lung cancer, all of whom received RT utilizing 3D planning tools, and investigated the correlation between DVH-based factors and RP rates. In total, 39 (19\%) of the 201 patients developed RP. Univariate and multivariate analyses indicated that $\mathrm{V}_{30}$ and MLD were the only factors significantly associated with RP rates. An increasing rate of RP was observed with increasing $V_{30}$ (RP rates: 6 and $24 \%$ in patients with $V_{30}$ of $\leq 18$ and $>18 \%$, respectively) and MLD values (RP rates: $10,16,27$ and $44 \%$ in patients who received an MLD of $<10$, 11-20, 21-30 and $>30 \mathrm{~Gy}$, respectively). The authors concluded that dosimetric factors were the best predictors of RP, superior to clinical factors (age, gender, tumor location, chemotherapy application, smoking, pre-RT forced expiratory volume in $1 \mathrm{sec}$ and performance status) for lung cancer patients treated with 3DCRT (3). Barriger et al (4) reviewed dosimetric data 
from 243 patients with stage III NSCLC treated with concurrent cisplatin/etoposide chemoradiotherapy to examine the rates and predictive factors for RP. In that study, 17 (7\%) of the patients developed grade $\geq 2 \mathrm{RP}$ according to the Common Terminology Criteria for Adverse Events (CTCAE) version 3.0. The median MLD, $\mathrm{V}_{5}, \mathrm{~V}_{20}$ and $\mathrm{V}_{30}$ values were $18 \mathrm{~Gy}, 52,35$ and $29 \%$, respectively. An increasing rate of RP was associated with increasing MLD (MLD <18 Gy, 2.2\% RP rate; MLD $>18$ Gy, $19 \%$ RP rate; $\mathrm{P}=0.015)$ and $\mathrm{V}_{20}\left(\mathrm{~V}_{20}<35 \%, 4.8 \%\right.$ $\mathrm{RP}$ rate; $\mathrm{V}_{20}>35 \%, 17 \% \mathrm{RP}$ rate; $\left.\mathrm{P}=0.097\right)$. Thus, the results revealed that an MLD >18 Gy was a predictive factor for RP, and that $\mathrm{V}_{20}$ was possibly associated with RP. Furthermore, a recent meta-analysis performed on 836 patients who received concurrent chemoradiotherapy obtained a similar outcome; the results suggested that $29.8 \%$ of patients developed symptomatic RP, and that $\mathrm{V}_{20}$ was a significant factor in predicting symptomatic $\mathrm{RP}(\mathrm{P}=0.008)$ (33).

In previous studies, most of the $\mathrm{V}_{\text {dose }}$ and MLD values used standardly refer to the bilateral lungs, which means that each dosimetric parameter represents the average value of the total lung parenchyma, rather than that of the unilateral lung with the primary tumor (2-5). Therefore, it is necessary to establish new parameters for use in treatment planning to aid in concentrating the radiation beams on a single lung. Ramella et al (5) analyzed 97 patients with locally advanced NSCLC who received complete 3DCRT with $\mathrm{V}_{20}, \mathrm{~V}_{30}$ and MLD limits of $31 \%, 18 \%$ and $20 \mathrm{~Gy}$, respectively. The authors investigated novel parameters $\mathrm{V}_{20}$ ipsi and $\mathrm{V}_{30}$ ipsi (percentages of ipsilateral lung volume receiving $>20$ and $>30 \mathrm{~Gy}$, respectively), which were indicated to be significant predictors of RP. The cutoff points for $\mathrm{V}_{20}$ ipsi and $\mathrm{V}_{30}$ ipsi were 52 and $39 \%$, respectively: The risk of RP was $9 \%$ if $\mathrm{V}_{20}$ ipsi was $\leq 52 \%$ vs. $46 \%$ if $\mathrm{V}_{20}$ ipsi was $>52 \%$; and the risk of RP was $8 \%$ if $\mathrm{V}_{30}$ ipsi was $\leq 39 \%$ vs. $38 \%$ if $\mathrm{V}_{30}$ ipsi was $>39 \%$. The differences in $\mathrm{V}_{20}$ ipsi and $\mathrm{V}_{30}$ ipsi between the RP group and the non-RP group were statistically significant $(\mathrm{P}=0.010$ and $\mathrm{P}=0.001$, respectively). Furthermore, in their clinical practice, RP incidence was reduced from 14.4 to $6.8 \%$ when adding the ipsilateral constraints to standard lung dosimetric parameters. Thus, this may be an accessible way to improve treatment planning.

Despite the numerous studies confirming the predictive value of dosimetric factors, certain studies have presented contrasting findings. Rodrigues et al (2) conducted a review of 12 studies to assess the association between DVH parameters and RP rates. The study showed a negative result, and the overall accuracy, sensitivity, specificity and positive predictive value of DVH parameters were found to be undesirable. Each DVH parameter in that study failed to predict RP alone or in a model with additional variables. Another meta-analysis also suggested that dose-volume metrics should be explored further to evaluate the RP risk (12).

NTCP. NTCP is another parameter that can be calculated as a function of the normal tissue DVH by different algorithms. Various studies have demonstrated that NTCP is a strong predictor of RILI (46). The Lyman model (47) is the most widely applied NTCP model, and is characterized by the binary (yes/no) toxicity evaluation endpoint (48). Although it is successful in estimating RP rates, there remains potential to improve the standard Lyman model. Recent studies have attempted to incorporate clinical risk factors in the model to better predict RILI. Tucker et al (48) introduced a generalized model accounting for censored time-to-toxicity data and smoking status, and the results demonstrated a higher predictive value of NTCP model compared with the model developed on DVH alone. Adding single-nucleotide polymorphisms to the standard Lyman model also enhanced its predictive value for RP (43).

Serum markers. The pathogenesis of RP remains unclear; it is known to be a complex inflammatory process that involves the cellular interactions between lung parenchymal cells and circulating immune cells, mediated through a series of cytokines (49). Thus, the plasma levels of distinct cytokines may be of significance in identifying patients at risk of developing RILI. However, these cytokines are derived from the irradiated normal lung tissues as well as the tumor tissues, including the tumor cells themselves, the immune cells of the tumor microenvironment and the host stroma of NSCLC specimens, influencing the circulating plasma cytokine concentrations $(50,51)$. This indicates that further investigation is necessary to confirm the ability of cytokines in predicting RILI. IL-6 and TGF- $\beta$ are pro-inflammatory and profibrogenic cytokines, which have been extensively investigated in numerous studies, including human clinical reports and animal trials. The fluctuating IL- 6 and TGF- $\beta$ plasma levels measured before and during RT may be associated with the development of RILI (49).

Rübe et al (49) analyzed the TGF- $\beta 1$, TNF- $\alpha$, IL- $1 \beta$ and IL-6 circulating plasma levels in 52 patients with NSCLC (stage I-III) to explore the prognostic values for the development of RP. The Late Effects in Normal Tissue-Subjective Objective Management Analysis (LENT-SOMA) system (Table I) was used in the study, and the cytokine data was obtained before RT, weekly during RT, every 3 months during follow-up, and at the beginning of RP. In the study, $40 \%$ of patients developed RP, with 10 cases exhibiting RP of grade II or higher (grade II/III/IV, 3/6/1 patients). The study failed to confirm any correlation between TGF- $\beta 1$ or IL- 6 plasma levels and the probability of RP occurrence. However, it appeared to be possible to predict RILI when cytokines were combined with dosimetric factors. In a study by Stenmark et al (52), five cytokines (IL-1 $\beta$, IL-6, IL-8, TNF- $\alpha$ and TGF- $\beta 1$ ), in 58 NSCLC patients treated with definitive RT, were analyzed to ascertain their value as predictive factors for RILI. All cytokines were evaluated individually and in combination with physical dosimetric parameters. The results indicated that a low level of pre-treatment IL-8 was a significant predictor for RILI, while elevated TGF- $\beta 1$ resulting from radiation was mildly correlated with the development of RILI. The other three cytokines demonstrated no predictive value. However, the combined model, utilizing IL- 8 , TGF- $\beta 1$ and MLD, yielded an advanced capacity for predicting RILI compared with any variable alone $(\mathrm{P}<0.001)$. Therefore, the authors concluded that a model based on inflammatory cytokines and dosimetric parameters may estimate RILI accurately (52).

A number of studies have indicated that surfactant protein (SP) levels in the serum may be meaningful in predicting RILI. Takahashi et al (53) reported that SP-A and SP-D concentrations in RP patients were higher than those of non-RP patients 
Table I. Summary of generally used grading systems.

\begin{tabular}{|c|c|c|c|c|c|}
\hline \multirow[b]{2}{*}{ Criteria } & \multicolumn{5}{|c|}{ Grade } \\
\hline & 1 & 2 & 3 & 4 & 5 \\
\hline \multicolumn{6}{|l|}{ CTCAE 4.0} \\
\hline Pneumonitis & $\begin{array}{l}\text { Asymptomatic; } \\
\text { observations only }\end{array}$ & $\begin{array}{l}\text { Symptomatic; requires } \\
\text { medical intervention; } \\
\text { limited ADL }\end{array}$ & $\begin{array}{l}\text { Severe symptoms; } \\
\text { oxygen indicated; impair } \\
\text { patient self-care ADL }\end{array}$ & $\begin{array}{l}\text { Life-threatening } \\
\text { respiratory } \\
\text { dysfunction; } \\
\text { urgent intervention } \\
\text { indicated }\end{array}$ & Mortality \\
\hline $\begin{array}{l}\text { Pulmonary } \\
\text { fibrosis }\end{array}$ & $\begin{array}{l}\text { Mild hypoxemia; } \\
\text { pulmonary } \\
\text { fibrosis }<25 \%\end{array}$ & $\begin{array}{l}\text { Moderate hypoxemia; } \\
\text { pulmonary hypertension; } \\
\text { pulmonary fibrosis } \\
25-50 \%\end{array}$ & $\begin{array}{l}\text { Severe hypoxemia; } \\
\text { right-sided heart failure; } \\
\text { pulmonary fibrosis } \\
50-75 \%\end{array}$ & $\begin{array}{l}\text { Life-threatening } \\
\text { consequences; } \\
\text { assisted ventilation } \\
\text { indicated; pulmonary } \\
\text { fibrosis }>75 \%\end{array}$ & Mortality \\
\hline $\begin{array}{l}\text { RTOG: } \\
\text { Pneumonitis }\end{array}$ & Mild symptoms & $\begin{array}{l}\text { Persistent symptoms } \\
\text { requiring symptomatic } \\
\text { treatment }\end{array}$ & $\begin{array}{l}\text { Severe symptoms, } \\
\text { possibly requiring } \\
\text { intermittent } \mathrm{O}_{2} \text { or } \\
\text { steroids; evidence of } \\
\text { acute pneumonitis }\end{array}$ & $\begin{array}{l}\text { Severe symptoms } \\
\text { requiring continuous } \\
\mathrm{O}_{2} \text { or assisted } \\
\text { ventilation }\end{array}$ & - \\
\hline $\begin{array}{l}\text { RTOG/EORTC: } \\
\text { Fibrosis } \\
\text { (LENT-SOMA) }\end{array}$ & $\begin{array}{l}\text { Asymptomatic or } \\
\text { mild symptoms; } \\
\text { slight imaging } \\
\text { changes }\end{array}$ & $\begin{array}{l}\text { Moderate symptoms; } \\
\text { patchy imaging } \\
\text { changes }\end{array}$ & $\begin{array}{l}\text { Severe symptoms; } \\
\text { increased density } \\
\text { imaging changes }\end{array}$ & $\begin{array}{l}\text { Severe symptoms } \\
\text { requiring } \\
\text { continuous } \mathrm{O}_{2} \text { or } \\
\text { assisted ventilation }\end{array}$ & Mortality \\
\hline \multicolumn{6}{|l|}{ SWOG } \\
\hline Pneumonitis & $\begin{array}{l}\text { Imaging changes; } \\
\text { mild symptoms } \\
\text { without steroids }\end{array}$ & $\begin{array}{l}\text { Symptoms requiring } \\
\text { steroids or tap for } \\
\text { effusion }\end{array}$ & $\begin{array}{l}\text { Symptoms requiring } \\
\text { oxygen }\end{array}$ & $\begin{array}{l}\text { Symptoms requiring } \\
\text { assisted ventilation }\end{array}$ & Mortality \\
\hline Fibrosis & $\begin{array}{l}\text { Asymptomatic; } \\
\text { imaging } \\
\text { changes }\end{array}$ & - & $\begin{array}{l}\text { Imaging changes with } \\
\text { symptoms (also code } \\
\text { symptoms) }\end{array}$ & - & - \\
\hline
\end{tabular}

CTCAE 4.0, common terminology criteria for adverse events, version 4.0; RTOG, radiation therapy oncology group; EORTC, European organization for research and treatment of cancer; LENT-SOMA, late effects in normal tissue-subjective objective management analysis; SWOG, southwest oncology group; ADL, activities of daily living.

$(\mathrm{P}=0.0065$ and $\mathrm{P}=0.0011$, respectively), which suggested an RP-diagnostic value of these two variables. In an article analyzing the Radiation Therapy Oncology Group (RTOG) 91-03 trial, an elevated serum level of SP at $20 \mathrm{~Gy}$ and increased IL-6 serum density after 10 Gy radiation were considered predictive factors of grade $\geq 2$ acute lung toxicity (54).

Clinical risk factors for the development of RILI. Prediction of RILI is not only dependent on dosimetric factors or plasma cytokine levels, but may also be influenced by clinical risk factors. Patient characteristics, including age, gender, comorbidity, tumor location, performance status and smoking status, combined with treatment-related factors, such as chemotherapy schedule and surgery, comprise the clinical factors associated with RP. These factors have been widely investigated in previous studies: Pre-treatment Karnofsky performance status was associated with late lung toxicity (54), and chemotherapy $(\mathrm{P}<0.0001)$ and advanced age $(61-70$ years $)$ were notable predictive factors for RP (55), whereas pre-RT surgery demonstrated no effect on the development of RP (56). However, few reports of RILI to date have systematically elucidated these risk factors.

In order to study the clinical factors professionally, Vogelius et al (57) conducted a meta-analysis synthesizing data from 31 independent studies with available odds ratio (OR) data for RP, and provided a framework for this large amount of information. The results indicated that advanced age (OR, $1.7 ; \mathrm{P}<0.0001)$, disease located in middle or lower lobe $(\mathrm{OR}$, $1.9 ; \mathrm{P}=0.002)$ and the presence of comorbidities $(\mathrm{OR}, 2.3$; $\mathrm{P}=0.007$ ) were significantly associated with RP. Sequential chemotherapy scheduling was also associated with a higher risk of developing $\mathrm{RP}(\mathrm{OR}, 1.6 ; \mathrm{P}=0.01)$ than concomitant chemotherapy scheduling. Smoking status, which showed contrasting effects, was analyzed in two parts: Ongoing smoking could prevent lung cancer patients from developing $\mathrm{RP}(\mathrm{OR}, 0.6 ; \mathrm{P}=0.008)$; and a history of smoking indicated a 
non-significant protective effect against $\mathrm{RP}(\mathrm{OR}, 0.7 ; \mathrm{P}=0.06)$. No association of gender or surgery with RP development was confirmed in the study. This research demonstrated a method of synthesizing published clinical risk factor data across various studies, facilitating its analysis with regard to RP. Depending on the method, it may be beneficial to combine these factors with dosimetric factors in a multivariate model in future research to better understand the development of RP, and generate guidelines for clinical research.

\section{Grading systems}

Several toxicity scoring systems evaluating the clinical, functional and imaging changes of acute and late RILI have been used in various studies. CTCAE version 4.0 (58) is currently the most recommended set of guidelines by the National Cancer Institute. In addition, the RTOG and European Organization for Research and Treatment of Cancer (RTOG/EORTC) scoring system (designated as RTOG for brevity) (59), as well as the Southwest Oncology Group (SWOG) scoring system (60) are also generally applied (Table I). Other criteria from the Eastern Cooperative Oncology Group (61) and the World Health Organization (62) are also in use (63). In generally used systems, toxicity grades of 1, 4 and 5 similarly represent mild symptoms, lethal conditions, and mortality, respectively. However, the criteria vary for definitions of grades 2 and 3. RTOG grade 2 is described as a persistent cough requiring narcotic antitussive agents, while the grade 3 patients present with severe cough requiring steroid treatment. By contrast, in SWOG grade 2, steroid treatment is required. However, the CTCAE 4.0 system does not involve the utility of steroid agents. For late lung toxicity, RTOG criteria appear to be the easiest to follow among the scoring systems, as they depicts lung fibrosis together with pneumonitis in detail (64).

\section{Treatments}

In order to reduce the probability or mitigate the severity of RILI, a variety of strategies have been investigated, ranging from radiation techniques to pharmacological methods (1). As standard, modern radiation treatment planning techniques should be implemented to minimize the dose to normal lung tissues. Age, sex, tumor location, smoking status, pulmonary function, performance status and a number of other patient characteristics should also be considered $(1,16)$. Given the high rate of infection in these patients, antibiotics are used prophylactically (16). For established RILI, multiple agents are used empirically, and corticosteroids are a mainstay due to their anti-inflammatory effects; the common dose is 60-100 mg/day for 2 weeks, followed by an extended taper over 3-12 weeks (1). Although steroids are widely used in patients with RILI, there appears to be no evidence confirming its possible influence on long-standing fibrosis. Due to advances in understanding the molecular pathology of RILI, several promising prophylactic and therapeutic approaches for this disease have been proposed.

Cytoprotective agents. Amifostine, an analog of cysteamine, is the first broad-spectrum cytoprotectant to have been approved in various countries for clinical use (65). It is an organic thio-phosphate molecule. Following its dephosphorylation by vascular endothelial cell alkaline phosphatase, amifostine transforms into its biologically active metabolite. The metabolite exerts its biological actions via two approaches: Scavenging ROS generated following radiation, and protecting nucleic acids from alkylating or platinum-based drugs (65-67). Several clinical trials have reported that amifostine could significantly reduce the incidence of RILI without compromising the anti-tumor efficacy of radiation in lung cancer patients $(13,66,67)$. Komaki et al $(13)$ reported that no severe $\mathrm{RP}$ was observed in patients with lung cancer in the amifostine treatment group, compared with $16 \%$ of patients not treated with amifostine $(\mathrm{P}=0.02)$. Furthermore, amifostine did not exhibit any apparent effects on survival in these patients. The authors thus concluded that amifostine had no tumor-protective effect. Recently, Koukourakis et al (68) demonstrated that a moderate dose of amifostine administered subcutaneously to irradiated postmastectomy patients had a significant effect in preventing fibrosis in lung and soft tissue.

Superoxide dismutases (SODs) are natural enzymes in mammals that converting superoxide radicals into oxygen and hydrogen peroxide $\left(\mathrm{H}_{2} \mathrm{O}_{2}\right)$ prior to further metabolism. In humans, three forms of SOD exist: Mn SOD, $\mathrm{Cu} / \mathrm{Zn}$ SOD and extracellular (EC) SOD (17). EC SOD is the major extracellular antioxidant enzyme and is highly produced in type II pneumocytes. Therefore, in the lungs, type II pneumocytes may play a critical role in cytoprotection via EC SOD (69). Numerous studies have successfully demonstrated the effects of SOD administration on radiation-induced fibrosis (RIF). Delanian et al (70) showed for the first time that liposomal-form SOD (Lip-SOD) reversed RIF in a clinical trial. They treated 42 distinct zones of RIF, involving the skin and underlying tissues, with Lip-SOD in 34 patients. Regression was observed in $79 \%$ of the fibrotic zones, and treatment was well-tolerated. The stability of the response at 3 and 5 years was 95 and $70 \%$, respectively. Lefaix et al (71) suggested that two agents, Mn SOD and Cu/Zn SOD, exerted curative effects on RIF in animal models. Epperly et al (72) demonstrated that overexpression of Mn SOD in the lungs of transgenic mice pre-radiation could decrease the occurrence of irradiated lung alveolitis and fibrosis.

The anti-fibrotic properties of SODs may act via mediating TGF- $\beta 1$ repression and inducing the reversion of myofibroblasts into normal fibroblasts (73). In previous studies, SOD-mimetic agents were shown to alleviate RILI. For example, Gao et al (74) administered EUK-207, a SOD/catalase mimetic agent, to rats via subcutaneous injection, starting at 7 days after total-body irradiation and stopping prior to the development of pneumonitis. The results indicated that EUK-207 may act as a mitigator of RP and fibrosis. EUK-207 was also shown to diminish multiple vascular injuries in irradiated lungs in vivo for the first time (74). Pan et al (75) suggested that pretreatment with the recombinant protein SOD-TAT in mice demonstrated an advantage over amifostine in reducing RIF and improving quality of life.

Suppressors of the renin-angiotensin (RAS) system. Classically, in the RAS, biological effects are initiated by the interplay between kidney mesangial cell-generated renin (substrate) and liver-generated angiotensinogen (enzyme) 
in circulation, followed by the production of angiotensin (Ang) I, an inactive decapeptide. After being cleaved by angiotensin-converting enzyme (ACE), Ang I transforms into the effective Ang II, which binds to Ang II receptor type 1 $\left(\mathrm{AT}_{1}\right)$ or type $2\left(\mathrm{AT}_{2}\right)$ to exert its functions (including vasoconstrictor activity to regulate blood pressure) (76). Furthermore, mounting evidence indicates that Ang II is associated with the development of fibrosis via TGF- $\beta$ upregulation (77) and ECM protein synthesis (78). Ang II also contributes to the injury process as a powerful proinflammatory substance (79). Thus, ACE inhibitor (ACEI), which blocks Ang II synthesis, may play a significant role in alleviating RILI. Ghosh et al (14) indicated that the ACEI captopril could increase survival and ameliorate RILI, including increased breath rate, vascular reactive changes and histopathological evidence, in irradiated mice. In a randomized controlled trial, application of captopril in 55 patients demonstrated a favorable efficacy in reducing pulmonary-related mortality resulting from total-body irradiation (80). However, captopril is a special type of ACEI, as the sulfhydryl group in its molecular structure was shown to be capable of scavenging radicals (81), which suggested another mechanism by which captopril could attenuate RILI. Wang et al (82) retrospectively analyzed 413 irradiated NSCLC patients, of whom 65 were given ACEIs during RT (only 1 received captopril), and the results suggested lower symptomatic RP rates in ACEI-treated patients compared with the non-ACEI-treated group. This outcome indicated that ACEI agents other than captopril could also reduce RILI. From another perspective, Molteni et al (83) showed that Ang II receptor inhibitors were helpful in palliating RILI. Additionally, certain researchers suggested renin as a profibrotic mediator independent from the angiotensin system, in the lung and other organs, which may provide another approach to mitigating lung fibrosis $(84,85)$.

Statins. HMG-CoA-reductase inhibitors (statins) are pleiotropic drugs mainly used as interventions for hypercholesterolemia. Other than lowering blood lipid levels, they have functions in reducing radiation-related proinflammatory and profibrotic responses as well as apoptosis, in vitro and in vivo $(86,87)$. A pharmacological use of statins involves inhibition of the radiation-induced activation of the transcription factor nuclear factor $\kappa \mathrm{B}$, and of the resulting overproduction of cytokines (including IL-6 and TNF- $\alpha$ ) (88). Pre-treatment with lovastatin in irradiated murine models achieved a reduction of endothelial selectin and intercellular adhesion molecule 1, which are important mediators in the inflammatory process (87). On the genetic level, simvastatin reversed the radiation-induced dysregulation of gene expression (such as p53, NRF2, and sphingolipid metabolic pathway genes) in rat lungs (89). In addition, statins showed an improved repair capacity for radiation-induced DNA double-strand breaks (88). Clinically, Wedlake et al (90) indicated that, among 308 patients who received pelvic RT for cancer, statin $(\mathrm{P}=0.04)$ and statin + ACEI $(\mathrm{P}=0.008)$ treatment regimens significantly relived radiation-induced acute gastrointestinal symptoms and exhibited long-term protective effects. Given the well-established clinical use of statins for lipid-lowering purposes, it is desirable to assess their application as radioprotectants in humans.
Growth factor-related protocols. TGF- $\beta / \mathrm{Smad}$ signaling is important in the development of radiation-induced damage, and has been investigated as a treatment target in numerous studies. Pentoxifylline (PTX), a xanthine derivative, appears to mitigate fibrosis by blocking Smad3/4-activated transcription (91). In a clinical trial by Ozturk et al (15), 40 patients with thoracic malignancies were randomly assigned to receive PTX (400 mg) or a placebo three times per day during the entire RT period. The results showed a statistically significant protective effect of PTX against acute and late lung radiotoxicity. In that study, the initial curative mechanism of PTX was suggested to be platelet reaggregation and TNF inhibition. Furthermore, Misirlioglu et al (92) used a combined therapy of PTX and $\alpha$-tocopherol (vitamin E) for lung cancer patients during and for 3 months after RT, which considerably ameliorated RILI. SB203580 and WP631 are blockers of Smad signal transduction pathway. They abrogate excessive proliferation, decrease the expression of p21 and plasminogen activator inhibitor-1 following radiation, and reduce TGF- $\beta 1$ in human lung fibroblasts (93). SM16 (94) and LY2109761 (95) are two small-molecule TGF- $\beta$ inhibitors which have been confirmed to be valuable in alleviating RILI based on different biological rationales.

Platelet-derived growth factor (PDGF) receptor tyrosine kinase inhibitors (RTKIs) are reportedly beneficial in mitigating RILI. Abdollahi et al (96) applied three different PDGF RTKIs (SU9518, SU11657 or imatinib) to irradiated mice during the acute RP phase; markedly reversal of lung fibrosis development was observed based on the clinical, histological, and CT imaging results. In a further study by the same authors, which assessed whether imatinib administration following subsidence of acute inflammation was effective in attenuating lung fibrosis in mice, a positive result was obtained (97). In these two studies, the therapeutic effect of PDGF RTKIs was considered to be associated with the regulation of TGF- $\beta$. Furthermore, Thomas et al (98) noted that imatinib relieved alveolitis or fibrosis by means of preventing the mast cell influx into the lungs following irradiation in mice.

Other treatment schemes. Yazici et al (99) revealed that the use of vitamin D significantly reduced interstitial inflammation and collagen deposition in irradiated rat lungs, and that the corresponding alveolar structure and pneumocytes were protected. MSX-122, a novel inhibitor of C-X-C chemokine receptor type 4 , has demonstrated a benefit in suppressing radiation-induced fibrotic processes in mice (100). In addition to these pharmacological therapies, certain other approaches, including physiotherapy, hyperbaric oxygen therapy and impedance-controlled microcurrent therapy may be promising in reducing radiation-related late lung fibrosis (101).

\section{Conclusions}

RILI is a dynamic process characterized by RP and lung fibrosis. Clinically, dyspnea, non-productive cough and low-grade fever are the most typical symptoms of acute RP, accompanied by a decline in pulmonary function. The exact mechanisms of RILI remain unclear; hyperplasia of normal 
pneumocytes, and the overexpression of proinflammatory and profibrogenic cytokines are suspected causes. TGF- $\beta$ has been widely investigated for its multiple functions in the development of RILI, on the molecular asnd genetic levels, in recent years. CT imaging is a common method in evaluating RILI, while SPECT, MRI and PET are more sensitive means that have been studied recently. Several grading criteria, incorporating clinical manifestations, imaging findings, and proper treatment measures, are employed in estimating the severity of RILI. Aiming at the potential underlying mechanisms, novel approaches for the prevention and treatment of RILI are under research.

\section{Acknowledgements}

The present study was supported by the National Natural Science Foundation of China (grant nos. 81672974 and 81602719).

\section{References}

1. Graves PR, Siddiqui F, Anscher MS and Movsas B: Radiation pulmonary toxicity: From mechanisms to management. Semin Radiat Oncol 20: 201-207, 2010.

2. Rodrigues G, Lock M, D'Souza D, Yu E and Van Dyk J: Prediction of radiation pneumonitis by dose-volume histogram parameters in lung cancer-a systematic review. Radiother Oncol 71: 127-138, 2004.

3. Hernando ML, Marks LB, Bentel GC, Zhou SM, Hollis D, Das SK, Fan M, Munley MT, Shafman TD, Anscher MS and Lind PA: Radiation-induced pulmonary toxicity: A dose-volume histogram analysis in 201 patients with lung cancer. Int J Radiat Oncol Biol Phys 51: 650-659, 2001

4. Barriger RB, Fakiris AJ, Hanna N, Yu M, Mantravadi P and McGarry RC: Dose-volume analysis of radiation pneumonitis in non-small-cell lung cancer patients treated with concurrent cisplatinum and etoposide with or without consolidation docetaxel. Int J Radiat Oncol Biol Phys 78: 1381-1386, 2010.

5. Ramella S, Trodella L, Mineo TC, Pompeo E, Stimato G, Gaudino D, Valentini V, Cellini F, Ciresa M, Fiore M, et al: Adding ipsilateral V20 and V30 to conventional dosimetric constraints predicts radiation pneumonitis in stage IIIA-B NSCLC treated with combined-modality therapy. Int J Radiat Oncol Biol Phys 76: 110-115, 2010.

6. Robbins ME, Brunso-Bechtold JK, Peiffer AM, Tsien CI, Bailey JE and Marks LB: Imaging radiation-induced normal tissue injury. Radiat Res 177: 449-466, 2012.

7. Koenig TR, Munden RF, Erasmus JJ, Sabloff BS, Gladish GW, Komaki R and Stevens CW: Radiation injury of the lung after three-dimensional conformal radiation therapy. AJR Am J Roentgenol 178: 1383-1388, 2002.

8. Linda A, Trovo M and Bradley JD: Radiation injury of the lung after stereotactic body radiation therapy (SBRT) for lung cancer: A timeline and pattern of CT changes. Eur J Radiol 79: 147-154, 2011

9. McCurdy MR, Castillo R, Martinez J, Al Hallack MN, Lichter J, Zouain $\mathrm{N}$ and Guerrero T: [18F]-FDG uptake dose-response correlates with radiation pneumonitis in lung cancer patients. Radiothe Oncol 104: 52-57, 2012.

10. Shioya S, Tsuji C, Kurita D, Katoh H, Tsuda M, Haida M, Kawana A and Ohta Y: Early damage to lung tissue after irradiation detected by the magnetic resonance $\mathrm{T} 2$ relaxation time. Radiat Res 148: 359-364, 1997.

11. Ireland RH, Din OS, Swinscoe JA, Woodhouse N, van Beek EJ, Wild JM and Hatton MQ: Detection of radiation-induced lung injury in non-small cell lung cancer patients using hyperpolarized helium-3 magnetic resonance imaging. Radiother Oncol 97: 244-248, 2010 .

12. Zhang XJ, Sun JG, Sun J, Ming H, Wang XX, Wu L and Chen ZT: Prediction of radiation pneumonitis in lung cancer patients: A systematic review. J Cancer Res Clin Oncol 138: 2103-2116, 2012.
13. Komaki R, Lee JS, Milas L, Lee HK, Fossella FV, Herbst RS, Allen PK, Liao Z, Stevens CW, Lu C, et al: Effects of amifostine on acute toxicity from concurrent chemotherapy and radiotherapy for inoperable non-small-cell lung cancer: Report of a randomized comparative trial. Int J Radiat Oncol Biol Phys 58: 1369-1377, 2004.

14. Ghosh SN, Zhang R, Fish BL, Semenenko VA, Li XA, Moulder JE, Jacobs ER and Medhora M: Renin-Angiotensin system suppression mitigates experimental radiation pneumonitis. Int J Radiat Oncol Biol Phys 75: 1528-1536, 2009.

15. Ozturk B, Egehan I, Atavci S and Kitapci M: Pentoxifylline in prevention of radiation-induced lung toxicity in patients with breast and lung cancer: A double-blind randomized trial. Int $\mathrm{J}$ Radiat Oncol Biol Phys 58: 213-219, 2004.

16. López Rodríguez M and Cerezo Padellano L: Toxicity associated to radiotherapy treatment in lung cancer patients. Clin Transl Oncol 9: 506-512, 2007.

17. Tsoutsou PG and Koukourakis MI: Radiation pneumonitis and fibrosis: Mechanisms underlying its pathogenesis and implications for future research. Int J Radiat Oncol Biol Phys 66: 1281-1293, 2006.

18. Rubin P, Siemann DW, Shapiro DL, Finkelstein JN and Penney DP: Surfactant release as an early measure of radiation pneumonitis. Int J Radiat Oncol Biol Phys 9: 1669-1673, 1983.

19. Almeida C, Nagarajan D, Tian J, Leal SW, Wheeler K, Munley M, Blackstock $\mathrm{W}$ and Zhao $\mathrm{W}$ : The role of alveolar epithelium in radiation-induced lung injury. PLoS One 8: e53628, 2013.

20. Citrin DE, Shankavaram U, Horton JA, Shield W III, Zhao S Asano H, White A, Sowers A, Thetford A and Chung EJ: Role of type II pneumocyte senescence in radiation-induced lung fibrosis. J Natl Cancer Inst 105: 1474-1484, 2013.

21. Piguet PF: Is 'tumor necrosis factor' the major effector of pulmonary fibrosis? Eur Cytokine Netw 1: 257-258, 1990.

22. Sime PJ: The antifibrogenic potential of PPARgamma ligands in pulmonary fibrosis. J Investig Med 56: 534-538, 2008.

23. Grgic I, Duffield JS and Humphreys BD: The origin of interstitial myofibroblasts in chronic kidney disease. Pediatr Nephrol 27: $183-193,2012$

24. Nagarajan D, Melo T, Deng Z, Almeida C and Zhao W: ERK/GSK3 $\beta /$ Snail signaling mediates radiation-induced alveolar epithelial-to-mesenchymal transition. Free Radic Biol Med 52: 983-992, 2012.

25. Phillips RJ, Burdick MD, Hong K, Lutz MA, Murray LA, Xue YY, Belperio JA, Keane MP and Strieter RM: Circulating fibrocytes traffic to the lungs in response to CXCL12 and mediate fibrosis. J Clin Invest 114: 438-446, 2004.

26. Yano H, Hamanaka R, Nakamura M, Sumiyoshi H, Matsuo N and Yoshioka H: Smad, but not MAPK, pathway mediates the expression of type I collagen in radiation induced fibrosis. Biochem Biophys Res Commun 418: 457-463, 2012.

27. Fine A and Goldstein RH: The effect of transforming growth factor-beta on cell proliferation and collagen formation by lung fibroblasts. J Biol Chem 262: 3897-3902, 1987.

28. Hashimoto S, Gon Y, Takeshita I, Matsumoto K, Maruoka S and Horie T: Transforming growth Factor-betal induces phenotypic modulation of human lung fibroblasts to myofibroblast through a c-Jun-NH2-terminal kinase-dependent pathway. Am J Respir Crit Care Med 163: 152-157, 2001

29. Han G, Zhang H, Xie CH and Zhou YF: Th2-like immune response in radiation-induced lung fibrosis. Oncol Rep 26: 383-388, 2011

30. Yang K, Palm J, König J, Seeland U, Rosenkranz S, Feiden W Rübe $\mathrm{C}$ and Rübe CE: Matrix-metallo-proteinases and their tissue inhibitors in radiation-induced lung injury. Int J Radiat Biol 83: 665-676, 2007.

31. Ding NH, Li JJ and Sun LQ: Molecular mechanisms and treatment of radiation-induced lung fibrosis. Curr Drug Targets 14: 1347-1356, 2013.

32. Medhora M, Gao F, Jacobs ER and Moulder JE: Radiation damage to the lung: Mitigation by angiotensin-converting enzyme (ACE) inhibitors. Respirology 17: 66-71, 2012.

33. Palma DA, Senan S, Tsujino K, Barriger RB, Rengan R, Moreno M, Bradley JD, Kim TH, Ramella S, Marks LB, et al: Predicting radiation pneumonitis after chemoradiation therapy for lung cancer: An international individual patient data meta-analysis. Int J Radiat Oncol Biol Phys 85: 444-450, 2013.

34. Mehta V: Radiation pneumonitis and pulmonary fibrosis in non-small-cell lung cancer: Pulmonary function, prediction, and prevention. Int J Radiat Oncol Biol Phys 63: 5-24, 2005. 
35. Marks LB, Fan M, Clough R, Munley M, Bentel G, Coleman RE, Jaszczak R, Hollis D and Anscher M: Radiation-induced pulmonary injury: Symptomatic versus subclinical endpoints. Int J Radiat Biol 76: 469-475, 2000.

36. Goethals I, Dierckx R, De Meerleer G, De Sutter J, De Winter O, De Neve W and Van de Wiele C: The role of nuclear medicine in the prediction and detection of radiation-associated normal pulmonary and cardiac damage. J Nucl Med 44: 1531-1539, 2003.

37. Graham MV, Purdy JA, Emami B, Harms W, Bosch W, Lockett MA and Perez CA: Clinical dose-volume histogram analysis for pneumonitis after 3D treatment for non-small cell lung cancer (NSCLC). Int J Radiat Oncol Biol Phys 45: 323-329, 1999.

38. Libshitz HI and Shuman LS: Radiation-induced pulmonary change: CT findings. J Comput Assist Tomogr 8: 15-19, 1984.

39. Choi YW, Munden RF, Erasmus JJ, Park KJ, Chung WK, Jeon SC and Park CK: Effects of radiation therapy on the lung: Radiologic appearances and differential diagnosis Radiographics 24: 985-998, 2004.

40. Ghafoori P, Marks LB, Vujaskovic Z and Kelsey CR: Radiation-induced lung injury: Assessment, management, and prevention. Oncology (Williston Park) 22: 37-47, 52-53, 2008.

41. Zhang W, Wang J, Tang M, Pan J, Bai P, Lin D, Qian F, Lin F, Yang $X$ and Zhang S: Quantitative study of lung perfusion SPECT scanning and pulmonary function testing for early radiation-induced lung injury in patients with locally advanced non-small cell lung cancer. Exp Ther Med 3: 631-635, 2012.

42. Hart JP, McCurdy MR, Ezhil M, Wei W, Khan M, Luo D, Munden RF, Johnson VE and Guerrero TM: Radiation pneumonitis: Correlation of toxicity with pulmonary metabolic radiation response. Int J Radiat Oncol Biol Phys 71: 967-971, 2008.

43. Tucker SL, Li M, Xu T, Gomez D, Yuan X, Yu J, Liu Z, Yin M, Guan X, Wang LE, et al: Incorporating single-nucleotide polymorphisms into the Lyman model to improve prediction of radiation pneumonitis. Int J Radiat Oncol Biol Phys 85: 251-257, 2013

44. Siva S, Hardcastle N, Kron T, Bressel M, Callahan J, MacManus MP, Shaw M, Plumridge N, Hicks RJ, Steinfort D, et al: Ventilation/perfusion positron emission tomography-based assessment of radiation injury to lung. Int $\mathrm{J}$ Radiat Oncol Biol Phys 93: 408-417, 2015.

45. Waissi W, Noël G and Giraud P: Follow-up after lung stereotactic radiotherapy. Cancer Radiother 19: 566-572, 2015

46. Kim TH, Cho KH, Pyo HR, Lee JS, Zo JI, Lee DH, Lee JM, Kim HY, Hwangbo B, Park SY, et al: Dose-volumetric parameters for predicting severe radiation pneumonitis after three-dimensional conformal radiation therapy for lung cancer. Radiology 235: 208-215, 2005.

47. Lyman JT: Complication probability as assessed from dose-volume histograms. Radiat Res Suppl 8: S13-S19, 1985.

48. Tucker SL, Liu HH, Liao Z, Wei X, Wang S, Jin H, Komaki R, Martel MK and Mohan R: Analysis of radiation pneumonitis risk using a generalized Lyman model. Int J Radiat Oncol Biol Phys 72: 568-574, 2008

49. Rübe CE, Palm J, Erren M, Fleckenstein J, König J, Remberger K and Rübe C: Cytokine plasma levels: Reliable predictors for radiation pneumonitis? PLoS One 3: e2898, 2008.

50. Tisdale MJ: Cachexia in cancer patients. Nat Rev Cancer 2: 862-871, 2002

51. Kong F, Jirtle RL, Huang DH, Clough RW and Anscher MS Plasma transforming growth factor-betal level before radiotherapy correlates with long term outcome of patients with lung carcinoma. Cancer 86: 1712-1719, 1999.

52. Stenmark MH, Cai XW, Shedden K, Hayman JA, Yuan S, Ritter T, Ten Haken RK, Lawrence TS and Kong FM: Combining physical and biologic parameters to predict radiation-induced lung toxicity in patients with non-small-cell lung cancer treated with definitive radiation therapy. Int J Radiat Oncol Biol Phys 84: e217-e222, 2012

53. Takahashi H, Imai Y, Fujishima T, Shiratori M, Murakami S, Chiba H, Kon H, Kuroki Y and Abe S: Diagnostic significance of surfactant proteins A and D in sera from patients with radiation pneumonitis. Eur Respir J 17: 481-487, 2001.

54. Hartsell WF, Scott CB, Dundas GS, Mohiuddin M, Meredith RF, Rubin P and Weigensberg IJ: Can serum markers be used to predict acute and late toxicity in patients with lung cancer? Analysis of RTOG 91-03. Am J Clin Oncol 30: 368-376, 2007.
55. Parashar B, Edwards A, Mehta R, Pasmantier M, Wernicke AG, Sabbas A, Kerestez RS, Nori D and Chao KS: Chemotherapy significantly increases the risk of radiation pneumonitis in radiation therapy of advanced lung cancer. Am J Clin Oncol 34: 160-164, 2011.

56. Kocak Z, Yu X, Zhou SM, D'Amico TA, Hollis D, Kahn D, Tisch A, Shafman TD and Marks LB: The impact of pre-radiotherapy surgery on radiation-induced lung injury. Clin Oncol (R Coll Radiol) 17: 210-216, 2005.

57. Vogelius IR and Bentzen SM: A literature-based meta-analysis of clinical risk factors for development of radiation induced pneumonitis. Acta Oncol 51: 975-983, 2012.

58. US Department of Health and Human Services: Common Terminology Criteria for Adverse Events (CTCAE) .Version 4.0. National Institutes of Health, 2009.

59. Cox JD, Stetz J and Pajak TF: Toxicity criteria of the radiation therapy oncology group (RTOG) and the european organization for research and treatment of cancer (EORTC). Int J Radiat Oncol Biol Phys 31: 1341-1346, 1995.

60. Green S and Weiss GR: Southwest oncology group standard response criteria, endpoint definitions and toxicity criteria. Invest New Drugs 10: 239-253, 1992.

61. Eastern Cooperative Oncology Group. ECOG Common Toxicity Criteria. http://ecog.dfci.harvard.edu/general/common_tox. html.

62. S G: World Health Organization Handbook for reporting results of cancer treatment. WHO Offset Publication, 1979.

63. Tucker SL, Jin H, Wei X, Wang S, Martel MK, Komaki R, Liu HH, Mohan R, Chen Y, Cox JD and Liao Z: Impact of toxicity grade and scoring system on the relationship between mean lung dose and risk of radiation pneumonitis in a large cohort of patients with non-small cell lung cancer. Int J Radiat Oncol Biol Phys 77: 691-698, 2010.

64. Kong FM, Ten Haken R, Eisbruch A and Lawrence TS: Non-small cell lung cancer therapy-related pulmonary toxicity: An update on radiation pneumonitis and fibrosis. Semin Oncol 32 (2 Suppl 3): S42-S54, 2005.

65. Capizzi RL and Oster W: Chemoprotective and radioprotective effects of amifostine: An update of clinical trials. Int J Hematol 72: 425-435, 2000.

66. Antonadou D, Coliarakis N, Synodinou M, Athanassiou H, Kouveli A, Verigos C, Georgakopoulos G, Panoussaki K, Karageorgis $\mathrm{P}$ and Throuvalas N; Clinical Radiation Oncololgy Hellenic Group: Randomized phase III trial of radiation treatment + /- amifostine in patients with advanced-stage lung cancer. Int J Radiat Oncol Biol Phys 51: 915-922, 2001.

67. Antonadou D, Throuvalas N, Petridis A, Bolanos N, Sagriotis A and Synodinou M: Effect of amifostine on toxicities associated with radiochemotherapy in patients with locally advanced non-small-cell lung cancer. Int J Radiat Oncol Biol Phys 57: 402-408, 2003.

68. Koukourakis MI, Panteliadou M, Abatzoglou IM, Sismanidou K, Sivridis E and Giatromanolaki A: Postmastectomy hypofractionated and accelerated radiation therapy with (and without) subcutaneous amifostine cytoprotection. Int J Radiat Oncol Biol Phys 85: e7-e13, 2013.

69. Folz RJ, Guan J, Seldin MF, Oury TD, Enghild JJ and Crapo JD: Mouse extracellular superoxide dismutase: Primary structure, tissue-specific gene expression, chromosomal localization, and lung in situ hybridization. Am J Respir Cell Mol Biol 17: 393-403, 1997.

70. Delanian S, Baillet F, Huart J, Lefaix JL, Maulard C and Housset M: Successful treatment of radiation-induced fibrosis using liposomal $\mathrm{Cu} / \mathrm{Zn}$ superoxide dismutase: Clinical trial. Radiother Oncol 32: 12-20, 1994.

71. Lefaix JL, Delanian S, Leplat JJ, Tricaud Y, Martin M, Nimrod A, Baillet F and Daburon F: Successful treatment of radiation-induced fibrosis using $\mathrm{Cu} / \mathrm{Zn}-\mathrm{SOD}$ and $\mathrm{Mn}-\mathrm{SOD}$ : $\mathrm{An}$ experimental study. Int J Radiat Oncol Biol Phys 35: 305-312, 1996.

72. Epperly MW, Bray JA, Krager S, Berry LM, Gooding W, Engelhardt JF, Zwacka R, Travis EL and Greenberger JS: Intratracheal injection of adenovirus containing the human MnSOD transgene protects athymic nude mice from irradiation-induced organizing alveolitis. Int J Radiat Oncol Biol Phys 43: 169-181, 1999.

73. Vozenin-Brotons MC, Sivan V, Gault N, Renard C, Geffrotin C, Delanian S, Lefaix JL and Martin M: Antifibrotic action of $\mathrm{Cu} / \mathrm{Zn}$ SOD is mediated by TGF-beta1 repression and phenotypic reversion of myofibroblasts. Free Radic Biol Med 30: 30-42, 2001 
74. Gao F, Fish BL, Szabo A, Doctrow SR, Kma L, Molthen RC, Moulder JE, Jacobs ER and Medhora M: Short-Term Treatment with a SOD/catalase mimetic, EUK-207, mitigates pneumonitis and fibrosis after single-dose total-body or whole-thoracic irradiation. Radiat Res 178: 468-480, 2012.

75. Pan J, Su Y, Hou X, He H, Liu S, Wu J and Rao P: Protective effect of recombinant protein SOD-TAT on radiation-induced lung injury in mice. Life Sci 91: 89-93, 2012.

76. Lavoie JL and Sigmund CD: Minireview: Overview of the renin-angiotensin system-an endocrine and paracrine system. Endocrinology 144: 2179-2183, 2003.

77. Border WA and Noble NA: Interactions of transforming growth factor- and angiotensin II in renal fibrosis. Hypertension 31: 181-188, 1998.

78. Gómez-Garre D, Ruiz-Ortega M, Ortego M, Largo R, López-Armada MJ, Plaza JJ, González E and Egido J: Effects and interactions of endothelin-1 and angiotensin II on matrix protein expression and synthesis and mesangial cell growth. Hypertension 27: 885-892, 1996.

79. Suzuki Y, Ruiz-Ortega M, Lorenzo O, Ruperez M, Esteban V and Egido J: Inflammation and angiotensin II. Int J Biochem Cell Biol 35: 881-900, 2003.

80. Cohen EP, Bedi M, Irving AA, Jacobs E, Tomic R, Klein J, Lawton CA and Moulder JE: Mitigation of late renal and pulmonary injury after hematopoietic stem cell transplantation. Int J Radiat Oncol Biol Phys 83: 292-296, 2012.

81. Chopra M, Scott N, McMurray J, McLay J, Bridges A, Smith WE and Belch JJ: Captopril: A free radical scavenger. Br J Clin Pharmacol 27: 396-399, 1989.

82. Wang H, Liao Z, Zhuang Y, Xu T, Nguyen QN, Levy LB, O'Reilly M, Gold KA and Gomez DR: Do angiotensin-converting enzyme inhibitors reduce the risk of symptomatic radiation pneumonitis in patients with non-small cell lung cancer after definitive radiation therapy? Analysis of a single-institution database. Int J Radiat Oncol Biol Phys 87: 1071-1077, 2013.

83. Molteni A, Wolfe LF, Ward WF, Ts'ao CH, Molteni LB, Veno P, Fish BL, Taylor JM, Quintanilla N, Herndon B and Moulder JE: Effect of an angiotensin II receptor blocker and two angiotensin converting enzyme inhibitors on transforming growth factor-beta (TGF-beta) and alpha-actomyosin (alpha SMA) important mediators of radiation-induced pneumopathy and lung fibrosis. Curr Pharm Des 13: 1307-1316, 2007.

84. Huang Y, Wongamorntham S, Kasting J, McQuillan D, Owens RT, Yu L, Noble NA and Border W: Renin increases mesangial cell transforming growth factor-beta1 and matrix proteins through receptor-mediated, angiotensin II-independent mechanisms. Kidney Int 69: 105-113, 2006.

85. Montes E, Ruiz V, Checa M, Maldonado V, Melendez-Zajgla J, Montaño M, Ordoñez-Razo R, Cisneros J, García-de-Alba C, Pardo A and Selman M: Renin is an angiotensin-independent profibrotic mediator: Role in pulmonary fibrosis. Eur Respir J 39: 141-148, 2012.

86. Ran XZ, Ran X, Zong ZW, Liu DQ, Xiang GM, Su YP and Zheng HE: Protective effect of atorvastatin on radiation-induced vascular endothelial cell injury in vitro. J Radiat Res 51: 527-533, 2010.

87. Ostrau C, Hülsenbeck J, Herzog M, Schad A, Torzewski M, Lackner KJ and Fritz G: Lovastatin attenuates ionizing radiation-induced normal tissue damage in vivo. Radiother Oncol 92: 492-499, 2009.

88. Fritz G, Henninger C and Huelsenbeck J: Potential use of HMG-CoA reductase inhibitors (statins) as radioprotective agents. Br Med Bull 97: 17-26, 2011.
89. Mathew B, Huang Y, Jacobson JR, Berdyshev E, Gerhold LM, Wang T, Moreno-Vinasco L, Lang G, Zhao Y, Chen CT, et al: Simvastatin attenuates radiation-induced murine lung injury and dysregulated lung gene expression. Am J Respir Cell Mol Biol 44: 415-422, 2011.

90. Wedlake LJ, Silia F, Benton B, Lalji A, Thomas K, Dearnaley DP, Blake P, Tait D, Khoo VS and Andreyev HJ: Evaluating the efficacy of statins and ACE-inhibitors in reducing gastrointestinal toxicity in patients receiving radiotherapy for pelvic malignancies. Eur J Cancer 48: 2117-2124, 2012.

91. Lin SL, Chen RH, Chen YM, Chiang WC, Lai CF, Wu KD and Tsai TJ: Pentoxifylline attenuates tubulointerstitial fibrosis by blocking Smad3/4-activated transcription and profibrogenic effects of connective tissue growth factor. J Am Soc Nephrol 16: 2702-2713, 2005.

92. Misirlioglu CH, Demirkasimoglu T, Kucukplakci B, Sanri E and Altundag K: Pentoxifylline and alpha-tocopherol in prevention of radiation-induced lung toxicity in patients with lung cancer. Med Oncol 24: 308-311, 2007

93. Li Y, Song SL, Peng RY, Wang DW, Jin MH, Gao YB and Ma JJ: Effects of SB203580 and WP631 on Smad signal transduction pathway in lung fibroblasts after irradiation. Ai Zheng 27: 698-702, 2008 (In Chinese)

94. Anscher MS, Thrasher B, Zgonjanin L, Rabbani ZN, Corbley MJ, Fu K, Sun L, Lee WC, Ling LE and Vujaskovic Z: Small molecular inhibitor of transforming growth factor-beta protects against development of radiation-induced lung injury. Int J Radiat Oncol Biol Phys 71: 829-837, 2008.

95. Flechsig P, Dadrich M, Bickelhaupt S, Jenne J, Hauser K, Timke C, Peschke P, Hahn EW, Gröne HJ, Yingling J, et al: LY2109761 attenuates radiation-induced pulmonary murine fibrosis via reversal of TGF- $\beta$ and BMP-associated proinflammatory and proangiogenic signals. Clin Cancer Res 18: 3616-3627, 2012.

96. Abdollahi A, Li M, Ping G, Plathow C, Domhan S, Kiessling F, Lee LB, McMahon G, Gröne HJ, Lipson KE and Huber PE: Inhibition of platelet-derived growth factor signaling attenuates pulmonary fibrosis. J Exp Med 201: 925-935, 2005.

97. Li M, Abdollahi A, Gröne HJ, Lipson KE, Belka C and Huber PE: Late treatment with imatinib mesylate ameliorates radiation-induced lung fibrosis in a mouse model. Radiat Oncol 4: 66, 2009.

98. Thomas DM, Fox J and Haston CK: Imatinib therapy reduces radiation-induced pulmonary mast cell influx and delays lung disease in the mouse. Int J Radiat Biol 86: 436-444, 2010.

99. Yazici G, Yildiz F, Iskit A, Erdemli E, Surucu S, Firat P, Hayran M, Ozyigit G and Cengiz M: The effect of vitamin D prophylaxis on radiation induced pulmonary damage. J Radiat Res 52: 616-621, 2011.

100. Shu HK, Yoon Y, Hong S, Xu K, Gao H, Hao C, Torres-Gonzalez E, Nayra C, Rojas M and Shim H: Inhibition of the CXCL12/CXCR4-axis as preventive therapy for radiation-induced pulmonary fibrosis. PLoS One 8: e79768, 2013

101. O'Sullivan B and Levin W: Late radiation-related fibrosis: Pathogenesis, manifestations, and current management. Semin Radiat Oncol 13: 274-289, 2003. 